\title{
Análise de envoltória de dados para avaliação de eficiência e caracterização de tipologias em agricultura: um estudo de caso ${ }^{1}$
}

\author{
Eliane Gonçalves Gomes* \\ João Alfredo de Carvalho Mangabeira** \\ João Carlos Correia Baptista Soares de Mello***
}

Resumo: O uso de Análise de Envoltória de Dados (DEA) para medir eficiência de produtores agrícolas permite indicar quem é eficiente, as razões para a ineficiência e os produtores cujas práticas podem servir de referência para os ineficientes. Este artigo usa DEA para medir a eficiência de uma amostra de agricultores de Holambra, município do Estado de São Paulo. Área cultivada, emprego e uso de máquinas são os inputs do modelo e a renda líquida é o output. É usado DEA BCC para avaliação em dois modelos: global e por grupos.

Palavras-chave: Eficiência técnica; Programação linear; DEA; Tipologia de eficiência; Holambra.

Classificação JEL: C610, Q120.

Abstract: Farmers' relative efficiency evaluation can be useful to aid decision-making in agriculture. The use of Data Envelopment Analysis

\footnotetext{
* Doutora em Engenharia de Produção (Pesquisa Operacional) e pesquisadora da Empresa Brasileira de Pesquisa Agropecuária. eliane.gomes@embrapa.br

** Mestre em Planejamento e Desenvolvimento Rural Sustentável e pesquisador da Embrapa Monitoramento por Satélite. manga@cnpm.embrapa.br

*** Doutor em Engenharia de Produção (Pesquisa Operacional) e Professor Adjunto do Dep. de Eng. de Produção da Universidade Federal Fluminense. jcsmello@producao.uff.br ${ }^{1}$ Os autores agradecem ao CNPQ pelo apoio financeiro por meio do Edital CNPq 19/2004 - Universal, Processo nº 472838/2004-0
} 
(DEA) in this context allows the identification of inefficiencies sources and benchmark units. This paper used DEA to measure the efficiency of farmers' sample from Holambra, a São Paulo State municipality. Cultivated area, employment and machinery usage are the inputs and net income is the output. DEA BCC is used in two models: global and by groups.

Keywords: Technical efficiency; linear programming; DEA; Efficiency typology; Holambra.

Jel Classification: C610, Q120.

\section{Introdução}

A análise de eficiência de unidades produtivas tem importância tanto para fins estratégicos (comparação entre unidades produtivas), quanto para o planejamento (avaliação dos resultados do uso de diferentes combinações de fatores) e para a tomada de decisão (como melhorar o desempenho atual, por meio da análise da distância entre a produção atual e potencial, ou saber onde é melhor investir).

A eficiência de uma unidade produtiva é medida através da comparação entre os valores observados e os valores possíveis de seus produtos (saídas) e recursos (insumos). Esta comparação pode ser feita, em linhas gerais, pela razão entre a produção observada e a produção potencial máxima alcançável, dados os recursos disponíveis, ou pela razão entre a quantidade mínima necessária de recursos e a quantidade efetivamente empregada, dada a quantidade de produtos gerados. Combinações dessas razões podem igualmente prover informações importantes.

O uso de Análise de Envoltória de Dados (Data Envelopment Analysis - DEA) para medir a eficiência relativa de unidades produtivas temse mostrado bastante atrativo em diversos setores de aplicação. $\mathrm{O}$ emprego de modelos DEA em agricultura pode apoiar as decisões dos agricultores, ao indicar as fontes de ineficiência e as unidades que podem servir de referência às práticas adotadas, ou seja, na identificação de benchmarks, conforme apresentado, por exemplo, em Tupy, Yamaguchi (2002). Em Gomes et al. (2003a) encontra-se uma revisão sobre o estado da arte do uso de DEA em agricultura. 
Este artigo faz uso de DEA para medir a eficiência de uma amostra de 71 agricultores do município de Holambra, Estado de São Paulo. Os dados utilizados são aqueles originalmente usados para tipificação dos produtores rurais (MANGABEIRA, 2002), referentes ao ano de 2002 e obtidos por levantamento de campo, via questionários agro-socioeconômicos.

\section{Análise de envoltória de dados}

No estudo dos temas produtividade e eficiência em agricultura pode surgir a seguinte questão: existe erro em usar toneladas de grão por hectare como medida de eficiência de um produtor rural? Medidas desse tipo apresentam a deficiência de não considerarem outros recursos na medida de eficiência, como mão-de-obra, maquinarias, combustível, fertilizantes etc. (GOMES et al., 2003a). Além disso, encerram um erro conceitual ao não diferenciarem produtividade e eficiência, já que uma medida apresentada como razão de duas quantidades é uma medida de produtividade, enquanto a eficiência é adimensional (COELLI et al., 1998).

O uso desse tipo de medida na formulação de políticas pode resultar não só no uso excessivo dos recursos não incluídos na medida de eficiência, mas também na imposição de metas irreais.

A abordagem por DEA, que utiliza programação linear para estimar a fronteira eficiente (linear por partes), é capaz de incorporar diversos inputs (entradas, recursos, insumos ou fatores de produção) e outputs (saídas ou produtos) para o cálculo da eficiência de unidades tomadoras de decisão, designadas por DMUs (Decision Making Units). As propriedades estatísticas dos estimadores das funções de produção obtidas com o uso de DEA podem ser vistas em Souza (2003).

Os problemas de programação linear (PPLs) de DEA otimizam cada observação individual com o objetivo de calcular uma fronteira de eficiência, determinada pelas unidades eficientes. Essas unidades servem como referência ou benchmark para as unidades ineficientes.

Há dois modelos DEA clássicos. O modelo CCR (também conhecido por CRS ou constant returns to scale) trabalha com retornos constantes de escala (CHARNES et al., 1978) e assume proporcionalidade entre inputs e outputs. O modelo BCC (ou VRS), devido a Banker et al. (1984), considera retornos variáveis de escala, isto é, substitui o axioma da proporcionalidade pelo axioma da convexidade. 
Tradicionalmente são possíveis duas orientações radiais para esses modelos: orientação a inputs, quando se deseja minimizar os recursos disponíveis, sem alteração do nível de produção; orientação a outputs, quando o objetivo é aumentar os produtos, sem mexer nos recursos usados.

Existem duas formulações equivalentes para DEA. De forma simplificada, pode-se dizer que uma das formulações (modelo dos Multiplicadores) trabalha com a razão de somas ponderadas de produtos e recursos, com a ponderação escolhida de forma mais favorável a cada DMU, respeitando-se determinadas condições (ou seja, cada DMU é auto avaliada). A outra formulação (modelo do Envelope) define uma região viável de produção e trabalha com uma projeção de cada DMU na fronteira dessa região. Uma vez que são duais, esses dois problemas calculam a mesma eficiência.

Neste artigo, o modelo DEA a ser usado é o BCC, já que as unidades em avaliação apresentam diferenças de escala significativas. Em (1) e em (2) apresentam-se, respectivamente, o modelo DEA BCC dos Multiplicadores e do Envelope, com orientação a inputs, já que se deseja verificar se a produção atual justifica a quantidade de recursos empregados. Considera-se que cada DMU $k, k=1 . . n$, é uma unidade de produção que utiliza $m$ inputs $x_{i k}, i=1 \ldots m$, para produzir $s$ outputs $y_{j k}, j=1 \ldots s$.

$\operatorname{Max} h_{o}=\sum_{j=1}^{s} u_{j} y_{j o}-u_{*}$

sujeito a

$\sum_{i=1}^{m} v_{i} x_{i o}=1$

$-\sum_{i=1}^{m} v_{i} x_{i k}+\sum_{j=1}^{s} u_{j} y_{j k}-u_{*} \leq 0, \forall k$

$u_{j}, v_{i} \geq 0, \forall j, i$

$u_{*} \in \mathfrak{R}$ 


$$
\begin{aligned}
& \text { Min } h_{o} \\
& \text { sujeito a } \\
& h_{o} x_{i o}-\sum_{k=1}^{n} x_{i k} \lambda_{k} \geq 0, \forall i \\
& -y_{j o}+\sum_{k=1}^{n} y_{j k} \lambda_{k} \geq 0, \forall j \\
& \sum_{k=1}^{n} \lambda_{k}=1 \\
& \lambda_{k} \geq 0, \forall k
\end{aligned}
$$

Em ambas as formulações $h_{o}$ é a eficiência da DMU $o$ em análise; $x_{i o} \mathrm{e}$ $y_{j o}$ são os inputs e outputs da DMU $o$. Em (1), $v_{i}$ e $u_{j}$ são os pesos calculados pelo modelo para inputs e outputs, respectivamente; $\mathbf{u}_{*}$ é a variável dual associada à condição $\sum_{k=1}^{n} \lambda_{k}=1$ da formulação (2) e é interpretado como fator de escala: quando positivo, indica retornos decrescentes de escala; quando negativo, indica retornos crescentes de escala; caso seja nulo, a situação é de retornos constantes de escala. Em (2), $\lambda_{k}$ representa a contribuição da DMU $k$ na formação do alvo da DMU $o$.

\section{Agricultura em Holambra}

Holambra, município do Estado de São Paulo, situa-se a $145 \mathrm{~km}$ da capital, na região centro leste do estado, a $22^{\circ} 37^{\prime} 55^{\prime \prime}$ de latitude sul e $47^{\circ} 03^{\prime} 36^{\prime \prime}$ de longitude oeste.

Tem aproximadamente $65 \mathrm{~km}^{2}$, com uma altitude média de $600 \mathrm{~m}$. É banhado pelos rios Jaguari, Camanducaia e Pirapitingui, além de diversos córregos e riachos, que se estendem num relevo relativamente plano, com uma altitude média de 600 m (HOLAMBRA, 1998).

O município é limitado pelos municípios de Artur Nogueira, Cosmópolis, Santo Antônio da Posse e Jaguariúna. As duas principais rodovias que passam pelo município são a SP-340 (Adhemar de Barros) e a SP107. Sua população é de 7.211 habitantes, sendo 3.689 homens e 3.522 
mulheres, segundo o Censo Demográfico do IBGE de 2000 (INSTITUTO BRASILEIRO DE GEOGRAFIA E ESTATÍSTICA, 2002a).

O município caracteriza-se pela imigração holandesa ao Brasil (final da década de 1940) e tem economia baseada na atividade agropecuária, com predomínio das atividades hortícolas, citrícolas, plantas decorativas, flores, suinocultura, avicultura e laticínios. Segundo o Censo Agropecuário do IBGE de 1996 (INSTITUTO BRASILEIRO DE GEOGRAFIA E ESTATÍSTICA, 2002b), o município detinha aproximadamente 1.466,3 ha de culturas temporárias, 1.769,5 ha de culturas permanentes, 432,4 ha de pastagens, 89,6 ha de matas e florestas naturais e 13,81 ha de reflorestamentos. Possuía ainda um efetivo de aproximadamente 1.800 bovinos, 28 mil suínos e aproximadamente 792 mil aves.

O município apresenta dimensão territorial relativamente pequena em relação aos demais municípios brasileiros e quase toda sua produção agrícola advém de um grupo aproximado de 287 produtores, com 20 ha em média de área (HOLAMBRA, 1998).

Mangabeira (2002) mapeou o uso das terras do município de Holambra com base em imagens do satélite IKONOS II (do ano de 2000) e levantamentos de campo (em 2001). Com o uso de questionários de campo, levantou informações de 266 variáveis agro-socioeconômicas (que geraram 204 indicadores), para uma amostra de 74 produtores rurais.

De posse desses indicadores, Mangabeira (2002) tipificou essa amostra de produtores. Para tal, foi usada a Análise de Correspondência Múltipla (BISHOP et al., 1975), seguida da análise de cluster pelo método de Ward (EVERITT, 1974), para classificar os tipos de produtores agrícolas (MANGABEIRA, 2002; AZEVEDO et al., 2001).

\section{Modelagem e Resultados}

\subsection{Estruturação do problema}

Para estruturar um modelo DEA é necessário definir as unidades a serem avaliadas, as variáveis de avaliação (inputs e outputs) e o modelo DEA adotado (CCR, BCC, entre outros; orientação a inputs, a outputs etc.).

Na construção do modelo DEA deve-se atentar quais variáveis serão consideradas inputs e quais serão consideradas outputs. Muitas vezes 
uma variável representa algo que é produzido, mas cuja quantidade deve ser minimizada (ex. acidentes, poluição). Nesses casos, essa variável é um output indesejável (GOMES, 2003) e uma das formas de tratá-la é considerá-la como um input. De forma geral, as variáveis que se desejam minimizar são consideradas inputs, e outputs caso contrário.

Um modelo com grande número de variáveis pode acarretar outro problema, qual seja, uma avaliação extremamente benevolente, com várias DMUs $100 \%$ eficientes. Existe uma recomendação empírica que o número de DMUs seja pelo menos o dobro ou o triplo do número de variáveis. Estudos mais recentes (GONZÁLEZ ARAYA, 2003) indicam que essa relação deve ser ainda maior (4 a 5 vezes), em especial quando, além do índice de eficiência, deseja-se analisar os benchmarks das unidades em avaliação.

Para a avaliação dos agricultores de Holambra foram selecionados 4 dos 206 indicadores definidos por Mangabeira (2002). Essas variáveis indicam as relações clássicas entre produção, capital e trabalho. Como inputs foram selecionados Área Cultivada (representada pela área ocupada com cultivos acrescida da área de pasto), em hectares, Emprego (expresso por homem-hora-ano) e Máquinas (calculado como número total de horas de uso de máquinas no ano). A Renda Líquida anual da propriedade, em reais, é o único output.

Para a escolha das DMUs deve-se observar a necessidade de uma certa homogeneidade entre elas. Dos 74 agricultores amostrados por Mangabeira (2002), apenas 3, por serem produtores de leite, não apresentam homogeneidade com o restante da amostra. Adicionalmente, estes produtores apresentaram valor negativo para a variável Renda Líquida, o que acarreta complicações teóricas aos modelos DEA (GONÇALVES, 2003; FIGUEIREDO, 2005). Por estas duas razões, os produtores de leite foram descartados desta análise. Restaram, portanto, 71 DMUs para serem analisadas.

O modelo selecionado foi o modelo DEA BCC orientado a inputs, já que há diferenças de escala significativas entre as DMUs e o objetivo é verificar se a produção obtida justifica a quantidade de recursos alocados. Os resultados do modelo DEA foram obtidos com o uso do software SIAD (ANGULO MEZA et al., 2005). 


\subsection{Resultados}

\subsubsection{Global}

É chamado resultado global aquele que considera a avaliação conjunta de todas as DMUs. Dos 71 produtores avaliados, 11 foram 100\% eficientes, dos quais 5 são produtores de flores. A eficiência média da amostra foi de $31,3 \%$; para os que produzem flores esse número reduziu-se para $27,4 \%$, e para os restantes aumentou para $34,4 \%$.

Analisando-se os resultados do modelo dos multiplicadores (pesos e fatores de escala), verifica-se uma grande quantidade de pesos zero, em especial para a variável "uso de máquinas" (67\% das DMUs). Isto significa que no cálculo da eficiência esta variável foi desconsiderada para que a DMU obtivesse a eficiência máxima possível, quando comparada com as demais. Tal fato mostra que poucos agricultores fazem bom uso das horas de máquinas (a maioria emprega horas de máquina em excesso). O problema dos pesos zero pode ser contornado com o emprego de modelos adicionais, como, por exemplo, avaliação cruzada (SEXTON et al., 1986; DOYLE, GREEN, 1995), modelos que incorporem restrições aos pesos dos multiplicadores (ALLEN et al., 1997) ou considerem a avaliação pela fronteira invertida (ENTANI et al., 2002; NOVAES, 2002; LETA et al., 2005). Revisões completas desses métodos podem ser vistas em Angulo Meza, Estellita Lins (2002) e em Leta et al. (2005). Neste artigo, no entanto, modelos adicionais não foram empregados, optando-se por interpretar apenas a sua ocorrência.

Cabe, no entanto, destacar que para o caso dos agricultores eficientes, os pesos resultantes não são únicos (nas DMUs extremo-eficientes os PPLs de DEA têm múltiplas soluções ótimas). Dessa forma, para as unidades eficientes, sem o emprego de técnicas adicionais, a análise de pesos fica comprometida. Destaca-se ainda que dentre as 11 DMUs eficientes, 6 são eficientes por default ou "falsamente eficientes", ou seja, são eficientes por apresentarem o menor valor em um dos inputs e/ou o maior valor do output; 1 DMU por apresentar menor valor no recurso “área cultivada" e 5 no input "uso de máquinas". Esta é uma característica inerente ao modelo DEA BCC, conforme destacado em Ali (1993), que pode ser contornada com o uso de modelos adicionais (por exem- 
plo, modelos que incorporem restrições aos pesos ou modelos que não incorporam a subjetividade do decisor, como a fronteira invertida).

Ainda em relação ao modelo dos multiplicadores, 2 produtores apresentaram retornos constantes de escala, 12 decrescentes e o restante retornos crescentes de escala. Isto mostra que para a maioria dos produtores avaliados, acréscimos na utilização de inputs (área cultivada, emprego e uso de máquina) acarretam aumentos significativos no valor da eficiência.

Os resultados do modelo do envelope (benchmarks e alvos) mostram que o produtor eficiente que aparece o maior número de vezes como referência para as outras unidades é um pequeno suinocultor e produtor de flores, com valores de área cultivada, emprego, uso de máquinas e renda líquida menores que a média dos produtores avaliados. Essa DMU pode servir como exemplo a ser seguido pelas unidades ineficientes, em especial, no que se refere às práticas de gestão dessa propriedade, por exemplo, na redução da mecanização agrícola e pela integração eficiente do esterco de suínos para produção de flores, o que otimiza a área cultivada.

Verifica-se ainda que diversas DMUs projetam-se em faces constituídas por DMUs eficientes que são produtores de especializações diversas (citricultores, floricultores, pecuaristas etc.). Isto torna-se importante na promoção da eficiência das DMUs ineficientes, já que estas devem observar não somente as práticas de seus "concorrentes diretos”, mas também aquelas dos demais produtores da região.

Em relação aos alvos, destaca-se uma das contribuições principais dos modelos DEA para a agricultura, qual seja, informar ao agricultor quais são as fontes de ineficiência e o que deve ser feito para a busca da eficiência. Por exemplo, para uma DMU que obteve $22,0 \%$ de eficiência, a recomendação para a busca da eficiência é a redução em 77,7\% da área cultivada, $84,5 \%$ do emprego e $91,5 \%$ do uso de máquinas, dado o valor de renda líquida atual. Desta forma, esse agricultor deve verificar em que etapa de seu processo produtivo (inclusive considerando outras variáveis não incluídas no modelo) ocorrem os gargalos que prejudicam seus resultados. Na Tabela 1 apresentam-se os percentuais médios de alteração que cada variável deve sofrer (inputs reduzir, output aumentar), por região da fronteira DEA BCC, para que as unidades ineficientes alcancem a eficiência. Destaca-se que na região de retornos 
constantes de escala, todas as DMUs são DEA eficientes e, por isso, não há indicação para alteração no valor das variáveis. Para a variável "renda líquida", as alterações são devido à projeção em faces não Pareto-eficientes (presença de folgas diferentes de zero), o que faz com que, apesar de o modelo ser orientado a inputs, seja indicado aumento do output para alcance da eficiência.

Tabela 1. Alterações percentuais (\%) nos valores das variáveis por região da fronteira

\begin{tabular}{ccccc}
\hline \multicolumn{5}{c}{ Retornos de escala } \\
\hline Variáveis & Crescentes & Constantes & Decrescentes & “Global” \\
\hline Área cultivada (ha) & $(-) 73,6$ & 0,0 & $(-) 68,4$ & $(-) 47,3$ \\
Emprego (homem-hora-ano) & $(-) 71,3$ & 0,0 & $(-) 67,8$ & $(-) 46,4$ \\
Máquinas (hora.ano) & $(-) 79,4$ & 0,0 & $(-) 67,2$ & $(-) 48,9$ \\
Renda líquida (R\$) & $(+) 308,0$ & 0,0 & 0,0 & $(+) 102,7$ \\
\hline
\end{tabular}

(-) decréscimo; (+) acréscimo.

Os resultados dos modelos DEA (em especial, eficiência, benchmarks e alvos) de cada um dos produtores ineficientes, se repassados a um agente de serviço de extensão rural que atue na região, podem ajudar na promoção da eficiência desses agricultores. Conforme apresentado no parágrafo anterior, é possível indicar a que nível cada variável deve chegar para que aquele produtor torne-se eficiente, e o agente de extensão pode indicar a melhor forma para alcançar aquele resultado (neste artigo, foi destacado apenas o exemplo do agricultor com $22,0 \%$ de eficiência e valores médios de alteração devido à limitação de espaço; os resultados completos podem ser obtidos com os autores). Os valores médios da Tabela 1 podem servir como uma primeira aproximação do extensionista junto ao agricultor na busca da eficiência, caso as indicações individuais sejam muito superiores aos valores médios.

Além dessas informações, aquelas outras coletadas no questionário podem igualmente subsidiar estratégias de aumento de eficiência, em especial se forem comparadas com aquelas dos produtores benchmarks daquele produtor ineficiente. A descrição dos perfis de agricultores eficientes e ineficientes com as variáveis disponíveis da pesquisa de campo, pode ajudar a identificar quais outras características chave distanciam esses dois grupos e, a partir disso, promover a redução dessa distância. 
Um outro ponto a ressaltar é a possibilidade de o agricultor não ser capaz de alcançar de forma imediata o alvo que lhe é atribuído. Neste caso, uma busca seqüencial por alvos intermediários, conforme apresentado por Gomes et al. (2003b) e Gomes (2003), pode ser uma solução atrativa ao produtor rural para a busca de alvos realizáveis, ou seja, mais próximos à sua realidade.

Outro destaque deve ser dado à projeção de DMUs ineficientes em regiões não Pareto-eficientes, o que é verificado pela grande presença de folgas diferentes de zero, inclusive para o output. Para a projeção em somente faces Pareto-eficientes, modelos DEA avançados devem ser empregados como aqueles que usam programação multiobjetivo para seleção de alvos (ANGULO MEZA, 2002), que projetam as unidades ineficientes em faces de maior dimensão (GONZÁLEZ ARAYA, 2003), os que eliminam as regiões não Pareto-eficientes por meio de suavização da fronteira DEA (SOARES DE MELLO et al., 2004) e os modelos que trabalham com quantidades infinitesimais, os chamados modelos não arquimedianos (ESTELLITA LINS, ANGULO MEZA, 2000).

\subsubsection{Por Grupos}

Mangabeira (2002) identificou a existência de 6 tipos de produtores em Holambra: agrocitricultores, agrofloricultores, agropecuaristas, florescitricultores, floricultores, produtores agrianuais.

Para aumentar a homogeneidade das DMUs, uma segunda avaliação de eficiência foi realizada, segundo essas tipologias de agricultores. Assim, foram rodados 6 modelos DEA BCC, orientados a outputs, com número de DMUs igual ao número de agricultores em cada grupo. As variáveis do modelo são as mesmas usadas no modelo de avaliação global (inputs: área cultivada, emprego e uso de máquinas; output: renda líquida).

Esta análise permitiu verificar como os produtores comportam-se, em termos de eficiência técnica, dentro de seus grupos. A Tabela 2 resume os resultados obtidos, que mostram que dentre os agricultores que produzem flores, os mais eficientes são os do tipo Agrofloricultores; dentre os que não produzem flores, os Agrocitricultores são os de maior eficiência técnica. Isto justifica-se pelo fato de estes dois tipos de produtores diversificarem suas produções e usarem mais racionalmente suas áreas cultivadas. 
Análise de envoltória de dados para avaliação de eficiência e caracterização de tipologias em agricultura: um estudo de caso

Tabela 2. Resultado do modelo DEA BCC, segundo a avaliação por grupos

\begin{tabular}{cccc}
\hline Grupos & $\mathbf{N .}^{\mathbf{o}}$ total de DMUs & $\mathbf{N .}^{\mathbf{0}}$ de DMUs eficientes & $\begin{array}{c}\text { Eficiência média } \\
(\%)\end{array}$ \\
\hline Agrocitricultores & 14 & 4 & 72,2 \\
Agrofloricultores & 7 & 4 & 76,8 \\
Agropecuaristas & 4 & 3 & 87,5 \\
Florescitricultores & 24 & 6 & 63,2 \\
Floricultores & 13 & 4 & 64,5 \\
Produtores agrianuais & 9 & 3 & 60,8 \\
\hline
\end{tabular}

Destaca-se que no caso do grupo Agropecuaristas, o modelo DEA BCC orientado a inputs não foi capaz de discriminar bem entre unidades eficientes e ineficientes. Conforme anteriormente mencionado, esta é outra característica dos modelos DEA referente à relação entre o número de DMUs e número de variáveis.

De uma maneira geral, os produtores classificados como Agrofloricultores e Agrocitricultores podem ser considerados como pequenos produtores rurais empresariais e que apresentam, adicionalmente, as características socioeconômicas a seguir descritas. A caracterização dos demais grupos pode ser encontrada em Mangabeira (2002).

- Todos possuem telefones em suas propriedades e $85 \%$ possuem computadores. Isto permite a estes agricultores ter melhor acesso à informação, quando comparados aos demais produtores e, desta forma, podem adotar um referencial moderno e globalizado para eventuais decisões gerenciais da produção e mesmo para melhoria da qualidade de vida no campo;

- A área média total das propriedades é de aproximadamente 7,5 ha, com área média de 5,5 ha de citros e 0,8 ha em média de floricultura em estufas;

- Utilizam $63 \mathrm{~kg} / \mathrm{ha} / \mathrm{ano}$, em média, de defensivos agrícolas (entre inseticidas e fungicidas), sendo este considerado um índice elevado de uso de defensivos, principalmente em estufas com floricultura;

- Usam aproximadamente 5 toneladas de adubos/ha/ano;

- Quanto à condição social destes produtores, observa-se que todos são proprietários, têm energia elétrica e água encanada nas propriedades; $85 \%$ têm conta em banco; $72 \%$ têm crédito bancário, assistência técnica privada e usam mecanização agrícola; a totalidade dos produtores tem renda somente na atividade agrícola; 
- Empregam em média de 7 pessoas por propriedade;

- Quanto ao uso de tecnologias, todos fazem análises de solos e 72 \% empregam o manejo integrado de pragas e adubos orgânicos e verdes;

- Em relação ao meio ambiente, somente $43 \%$ têm área com mata nas propriedades; $100 \%$ não fazem rotação de culturas; somente $43 \%$ pensam em fazer reflorestamentos com espécies nativas; em nenhuma das propriedades há estação de tratamento de resíduos.

Os resultados do modelo dos multiplicadores para estes 6 grupos confirmam os resultados do modelo global de que poucos agricultores fazem bom uso das horas de máquinas. Esta variável recebeu a maior quantidade de pesos zero em 4 dos 6 modelos. Para os grupos Floricultores e Agrofloricultores, a variável área cultivada foi a que obteve maior número de pesos zero, o que mostra que a minoria dos agricultores desses grupos faz bom uso da terra.

A Tabela 3 traz os resultados de retornos de escala (quantidade de DMUs em cada faixa) para cada um dos grupos. Verifica-se que, analogamente à análise global, em todos os grupos, a maioria dos agricultores encontra-se em situação de produção em que decréscimos na utilização de recursos acarretariam aumentos substanciais na eficiência.

Tabela 3. Caracterização das DMUs segundo os retornos de escala e tipos de agricultor

\begin{tabular}{cccc}
\hline \multirow{2}{*}{ Grupo } & \multicolumn{3}{c}{ Retornos de Escala } \\
\cline { 2 - 4 } & Crescentes & Constantes & Decrescentes \\
\hline Agrocitricultores & 8 & 2 & 4 \\
Agrofloricultores & 4 & 2 & 1 \\
Agropecuaristas & 3 & 1 & 0 \\
Florescitricultores & 20 & 1 & 3 \\
Floricultores & 12 & 1 & 0 \\
Produtores agrianuais & 5 & 2 & 2 \\
\hline
\end{tabular}

A Tabela 4 apresenta as características do benchmark mais referenciado em cada grupo. Como já destacado, as DMUs de referência são importantes na análise de eficiência pois servem como exemplo a ser 
seguido pelas unidades ineficientes que buscam a eficiência.

Tabela 4. Características do benchmark mais referenciado em cada grupo

\begin{tabular}{|c|c|c|c|c|c|}
\hline Grupo & & $\begin{array}{c}\text { Área } \\
\text { cultivada } \\
\text { (ha) }\end{array}$ & $\begin{array}{c}\text { Emprego } \\
\text { (homem-hora-ano) }\end{array}$ & $\begin{array}{l}\text { Máquinas } \\
\text { (hora-ano) }\end{array}$ & $\begin{array}{l}\text { Renda } \\
\text { líquida } \\
(\mathrm{R} \$)\end{array}$ \\
\hline \multirow{2}{*}{ Agrocitricultores } & Benchmark & 7,3 & 219 & 36,5 & 21.028 \\
\hline & Média & 15,8 & 2.800 & 127 & 29.194 \\
\hline \multirow{2}{*}{ Agrofloricultores } & Benchmark & 1,0 & 1.500 & 0 & 27.000 \\
\hline & Média & 3,0 & 3.420 & 150 & 44.857 \\
\hline \multirow{2}{*}{ Agropecuaristas } & Benchmark & 1,0 & 300 & 0 & 66.000 \\
\hline & Média & 9,3 & 375 & 0 & 19.764 \\
\hline \multirow{2}{*}{ Florescitricultores } & Benchmark & 9,0 & 2.040 & 54 & 319.050 \\
\hline & Média & 70,7 & 27.793 & 2473 & 528.390 \\
\hline \multirow{2}{*}{ Floricultores } & Benchmark & 3,0 & 3.600 & 900 & 1.200 .000 \\
\hline & Média & 13,3 & 17.729 & 1.221 & 250.151 \\
\hline \multirow{2}{*}{$\begin{array}{l}\text { Produtores } \\
\text { agrianuais }\end{array}$} & Benchmark & 1,5 & 918 & 9 & 63.875 \\
\hline & Média & 13,5 & 2.082 & 61 & 17.676 \\
\hline
\end{tabular}

Abaixo complementam-se os dados da Tabela 4 com outras informações referentes ao agricultor mais referenciado (benchmark) em cada grupo.

- Agrocitricultor: A propriedade possui 7,3 ha de área total, com produção de somente citros. Usa defensivos, herbicidas, calcário, adubos, máquinas. Faz manejo integrado de pragas e usa sementes melhoradas. Tem água para a produção e não apontou problemas com energia elétrica. É cooperado, teve crédito rural e usa computador na agropecuária. Pensa em fazer reflorestamento com espécies nativas.

- Agrofloricultor: Produtor de flores com 2,0 ha de área total, sendo 1,0 ha de estufa. Possui telefone e computador em sua propriedade. É associado e recebe assistência técnica privada. Tem energia elétrica e água para produção; tem tanque para captação de água. Usa defensivos e adubos.

- Agropecuarista: Na propriedade de 2,5 ha, com 1,0 ha de granja, há telefone e fax. Emprega vermifugação e vacinas. É cooperado, associado, recebeu crédito rural e assistência técnica privada. Tem energia elétrica residencial e para produção. Tem água na propriedade.

- Florescitricultor: Produtor que tem 10,0 ha de área total, sendo 2,0 
ha de citros, 6,0 ha de cultura anual, 0,7 ha de estufa e 0,4 de granja. Emprega defensivos, herbicidas, calcário e adubos e máquinas. É associado, cooperado, sindicalizado e recebeu assistência técnica privada. Tem energia elétrica para a produção, com fornecimento deficitário; há fornecimento de água, mas não possui tanque para sua captação. Faz rotação de culturas e pensa em reflorestar a propriedade com espécies nativas.

- Floricultor: Nesta propriedade de 3,8 ha de área total, 3,0 ha são de estufas, com emprego de defensivos, adubos e máquinas. 0 produtor participa de cooperativas, recebe assistência técnica privada e teve crédito rural. Tem energia elétrica para a produção e água. Possui telefone, fax, computador e tanque para captação de água.

- Produtor agrianual: Este produtor possui telefone e fax em sua propriedade de 6,5 ha de área total, sendo 1,5 ha de cultivos com culturas anuais, nos quais não pratica rotação de culturas. Usa máquinas, adubação, defensivos e herbicidas. Participa de cooperativa e associação; recebeu assistência técnica privada. A propriedade tem fornecimento de energia elétrica e água, mas não tem tanque para sua captação.

Finalmente, uma análise interessante refere-se à classificação das unidades ineficientes. Poder-se-ia classificá-las, subjetivamente, como de baixa, média e alta eficiência, por exemplo. Uma alternativa é classificálas segundo a localização nas camadas de iso-eficiência. As camadas de iso-eficiência são usadas para obter uma forma alternativa de ordenação em DEA (TAVARES, 1998; BARR et al., 2000). As camadas são obtidas da seguinte forma (GOMES, 2003): as DMUs com 100\% de eficiência formam a camada 1. Essas DMUs são, então, retiradas do conjunto de análise e corre-se novamente o modelo DEA. As DMUs eficientes neste subconjunto formam a camada 2 . O processo repete-se até que todas as DMUs tenham sido retiradas do conjunto inicial.

Aqui, as camadas de iso-eficiência são usadas para a problemática da divisão em classes, de maneira análoga à abordagem de Soares de Mello et al. (2005). Dessa forma, este procedimento permite uma alocação não subjetiva das unidades produtivas segundo o grau de eficiência, e uma qualificação objetiva das unidades, segundo variáveis não consideradas no modelo DEA. A seguir, são caracterizados cada um dos grupos de 
agricultores identificados, incluindo-se a camada de iso-eficiência à qual pertencem, o número de DMUs no sub-grupo e a eficiência média das unidades da camada (em relação à fronteira de eficiência).

Agrocitricultores eficientes ( $1^{\text {a }}$ camada - 4 produtores - eficiência média 100,0\%): Todos são proprietários das terras, têm computadores para a agropecuária, são cooperados e têm energia elétrica residencial e água e energia para a produção. Não têm renda extra-agrícola. A área média total é de 12,2 ha; 4,6 ha de área média de citros e 4,5 ha de cultura anual. O custo total médio de citros por ano é de $\mathrm{R} \$ 9.727,33$; receita bruta média de citros $\mathrm{R} \$ 22.380,00$. Usam em média 72 horas de máquina anualmente e têm cerca de 3 empregados na propriedade. Esses proprietários não fazem rotação de culturas; empregam práticas de conservação do solo.

Agrocitricultores de alta eficiência ( $2^{\text {a }}$ camada -6 produtores - eficiência média $77,9 \%$ ): Todos são proprietários das terras e têm cerca de 4 empregados na propriedade anualmente. Têm mapas das propriedades (conhecem bem a propriedade), energia elétrica e água suficientes para produção. Vivem somente da agricultura, em uma área média total de 19,0 ha, com 11,1 ha de área média de citros e de cultura anual. O custo total de citros por ano é de $\mathrm{R} \$ 34.038,33$, com uma receita bruta de $\mathrm{R} \$$ $50.493,33$. Usam em média 75,6 horas de máquina, além de adubos, calcário, herbicidas e defensivos.

Agrocitricultores de média eficiência ( $3^{\text {a }}$ camada -2 agricultores - eficiência média 37,5\%): São cooperados e proprietários das terras. As propriedades têm área média total de 19,5 ha; área média de citros de 2,6 ha; área de cultura anual de 11,8 ha. Fazem rotação de culturas, usam calcário e adubos. O custo total da produção de citros por ano é de $\mathrm{R} \$$ $6.700,00$ e a receita bruta $R \$ 15.080,00$. O uso de máquinas é em média de 96,8 horas, e mantêm cerca de 3 empregos na propriedade por ano.

Agrocitricultores de baixa eficiência (4a camada - 2 agricultores - eficiência média 33,9\%): Todos são cooperados e têm computadores. A área média total das propriedades é de 22,5 ha, com 15,0 ha de área de citros (custo total por ano de $\mathrm{R} \$ 9.466,00$ e receita bruta de $\mathrm{R} \$ 18.932,00$ ) e 11,8 ha de cultura anual. Usam defensivos, herbicidas, adubos e calcário, além de cerca de 275,2 horas de uso de máquina. Têm em média 31 empregos na propriedade anualmente. 
Agrofloricultores eficientes (camada 1 - 4 agricultores - eficiência média 100,0\%): Estes produtores têm área média de 4,0 ha, com 0,7 ha de área de estufa (não há cultivo de flor no campo). O emprego médio anual é de 12 pessoas. Usam defensivos, adubos e máquinas. O custo total médio anual por estufa é de $\mathrm{R} \$ 208.000,00$, com uma renda bruta de $\mathrm{R} \$ 276.750,00$. Todos possuem contabilidade e são proprietários do imóvel rural. Têm energia elétrica para produção, energia e água nas residências. Não fazem rotação de culturas e não têm estação de tratamento de resíduos.

Agrofloricultores de média eficiência (camada 2 - 2 produtores - eficiência média 48,1\%): São agricultores proprietários do imóvel, com dedicação exclusiva, e possuem escrituração ou mapa da área. São cooperados e recebem assistência técnica privada. A área total média é de 8,2 ha, com 0,8 ha em média com flor no campo e 0,7 ha em média de área de estufa. O custo total médio do cultivo de flor no campo é de $\mathrm{R} \$ 52.000,00$ (renda bruta de $\mathrm{R} \$ 60.000,00$ ) e das estufas $\mathrm{R} \$ 258.200,00$ (renda bruta de $\mathrm{R} \$ 270.900,00)$. Empregam em média 10 pessoas anualmente.

Agrofloricultores de baixa eficiência (camada 3 - 1 produtor - eficiência 41,0\%): Este produtor, proprietário de seu imóvel rural, tem área total de 3,6 ha e 3,0 ha de flor no campo. Tem um custo total com a produção de R 174 mil e uma renda bruta de R 180 mil. Participa de cooperativa, associação e sindicato. Emprega 12 pessoas por ano em sua propriedade. Não pensa em fazer reflorestamento com espécies nativas.

Agropecuaristas eficientes ( $1^{\text {a }}$ camada -2 produtores - eficiência 100,0\% ): São suinocultores cooperados e associados, que recebem assistência técnica privada, e cujas propriedades têm área total média de 4,2 ha, com média de 2,0 ha de granja e 2,2 ha de pasto limpo. A produção média anual é de 1.920 animais, com o emprego médio anual de 1 pessoa, e que geram $R$ \$37.800,00 de renda líquida. Usam vermifugação e vacinas. Todos têm energia elétrica e água para a produção. Não têm renda fora da propriedade, nem estação de tratamento de resíduos.

Agropecuaristas de média eficiência (2a camada - 2 produtores - eficiência de 50,0\%): Esses produtores associados e sindicalizados têm propriedades de área total média de 20,3 ha, com de 0,2 ha de granja e 7,3 ha de pasto limpo. Possuem em média 27 bovinos de corte por ano, e empregam em média 1 pessoa anualmente. A renda líquida 
média dessa produção é de $\mathrm{R} \$ 1.152,00$. Têm energia elétrica e água para a produção, usam vacinas e mineralização e recebem assistência técnica privada.

Florescitricultores eficientes (camada 1 - 6 agricultores - eficiência média 100,0\%): Propriedades com área total média de 31,2 ha, com emprego médio anual de 31 pessoas. As áreas cultivadas médias são: 11,8 ha de citros; 13,4 ha de culturas anuais; 14,0 ha de flor no campo; 3,8 ha de área com estufa; 1,0 ha de área de reflorestamento. Alguns produtores têm avicultura de corte, postura e suinocultura. Todos são proprietários do imóvel rural, têm mapa ou escrituração da propriedade, são cooperados e recebem assistência técnica privada. Não têm atividade remunerada fora da propriedade. Têm telefone, computador, energia elétrica e água na propriedade. Empregam práticas de conservação da terra. Usam herbicidas, calcário, adubação e máquinas.

Florescitricultores de alta eficiência (camada 2 - 9 agricultores - eficiência média 65,1\%): Produtores que são donos de seus imóveis rurais e que participam de cooperativas. As propriedades têm energia elétrica e água e possuem área total média de 21,1 ha. As áreas cultivadas médias são: 9,9 ha de citros; 7,0 ha de culturas anuais; 6,0 ha de flor no campo; 1,4 ha de área com estufa; 0,8 ha de área de reflorestamento. Usam herbicidas, calcário, adubação e máquinas. Alguns produtores têm avicultura de corte e suinocultura. Empregam em média 24 pessoas anualmente.

Florescitricultores de média eficiência (camada 3 - 6 agricultores - eficiência média 33,4\%): Essas propriedades têm área total média de 24,8 ha, nas quais são empregadas em média 22 pessoas por ano. As áreas cultivadas médias são: 18,7 ha de citros; 18,3 ha de culturas anuais; 3,0 ha de flor no campo; 1,7 ha com estufas; 2,0 ha de reflorestamento. Alguns produtores têm suinocultura. Empregam herbicidas, calcário, adubação e máquinas. Têm energia elétrica, água, telefone e computadores nas propriedades.

Florescitricultores de baixa eficiência (camada 4 - 3 agricultores - eficiência média 31,8\%): Produtores proprietários dos imóveis rurais, cooperados e recebem assistência técnica privada. Propriedades com energia elétrica e água, com área total média de 29,1 ha. As áreas cultivadas médias são: 16,8 ha de citros; 10,5 ha de culturas anuais; 10,0 
ha de flor no campo; 2,1 ha de área com estufa. Alguns produtores têm avicultura de corte. Empregam em média anualmente 36 pessoas nas propriedades. Não têm renda extra-agrícola.

Floricultores eficientes ( $1^{\text {a }}$ camada - 4 produtores - eficiência 100,0\%): São todos agricultores cooperados, que recebem assistência técnica privada e crédito rural. São proprietários dos imóveis, que têm telefone, água e energia elétrica, tanto para produção quanto na residência; têm mapa da propriedade. Usam computador na agropecuária. Empregam em média 35 pessoas propriedade por ano. A área média total das propriedades é de 6,1 ha, com o uso de 1,0 ha para cultivo de flor no campo e 2,3 ha de estufas. Empregam defensivos, adubos, calcário, máquinas e práticas de conservação do solo.

Floricultores de alta eficiência ( $2^{\text {a }}$ camada -6 produtores - eficiência média 52,8\%): Cultivam, em média, 1,8 ha de cultura anual, 0,7 ha de flor no campo e 4,2 ha de flores em estufas. A área total média das propriedades é de 16,0 ha, com 2,0 ha em média de reflorestamento. Usam defensivos, adubos, calcário e máquinas. Esses produtores são donos do imóvel, têm telefone e computador na propriedade.

Floricultores de média eficiência ( $3^{\mathrm{a}}$ camada -2 produtores - eficiência média 28,9\%): São proprietários do imóvel, têm telefone, computador, energia elétrica e água para produção. Cultivam 0,8 ha de flor no campo e 2,3 ha de flor em estufas, em uma área total média de 35,1 ha. Empregam em média 78 pessoas por ano. Usam defensivos, herbicidas, calcário, adubos e máquinas. São cooperados, associados, recebem assistência técnica, mas nenhum dos produtores recebeu crédito rural.

Floricultores de baixa eficiência ( $4^{\mathrm{a}}$ camada - 1 produtor - eficiência 19,3\%): Propriedade com 42,5 ha de área total, dos quais 8,0 ha são de estufas. Não cultiva flor no campo, mas tem 12,0 ha de cana-de-açúcar. Usa práticas de conservação do solo, herbicidas, defensivos, calcário, adubação e máquinas, e tem tanque para captação de água. Emprega em média 100 pessoas por ano.

Produtores agrianuais eficientes (camada 1 - 3 produtores - eficiência 100,0\%): Todos são proprietários do imóvel, fazem contabilidade da produção e participam de cooperativas. Têm água na propriedade, mas nem todos têm energia elétrica para produção. Em média, por ano, são empregadas 2 pessoas. As propriedades têm cerca de 6 ha de área total, 
com 2,5 ha de cultura anual e 0,8 ha de granja. O custo da produção de culturas anuais é, em média, de $\mathrm{R} \$ 1.640,00$ e uma renda bruta média de $\mathrm{R} \$ 3.900,00$. Usam herbicidas, calcário, adubos, máquinas e práticas de conservação do solo.

Produtores agrianuais de média eficiência (camada 2 - 5 produtores - eficiência média 45,0\%): A área total média das propriedades é de 23,2 ha, sendo 9,6 ha em média com culturas anuais (renda bruta de $\mathrm{R} \$$ $8.160,00$ e custo total $\mathrm{R} \$ 9.978,60$ ) e 5,0 ha com cana. Empregam anualmente, em média, 11 pessoas. Têm energia elétrica residencial e água para produção. São proprietários do imóvel e fazem contabilidade. Quase todos usam defensivos, herbicidas, calcário e máquinas na produção.

Produtores agrianuais de baixa eficiência (camada 3 - 1 produtor - eficiência 22,3\%): Agricultor proprietário do imóvel, sindicalizado, que tem água e energia elétrica para produção. Usa computador para a agropecuária. Emprega cerca de 5 pessoas por ano. A área total da propriedade é de 16,9 ha, com 10,0 ha de culturas anuais, com custo de produção de $\mathrm{R} \$ 11.500,00$. Usa defensivos, herbicidas, adubos, calcário e máquinas na produção.

\section{Conclusões}

O emprego do modelo DEA à avaliação dos agricultores de Holambra mostrou-se de bastante interesse, em especial no que se refere à possibilidade de determinar diretrizes aos agricultores ineficientes para o alcance da eficiência (redução dos recursos e/ou aumento da produção). Além disso, a indicação de unidades referência ou benchmarks e o cálculo dos alvos são importantes ferramentas para agentes de extensão rural, que podem auxiliar na indicação de qual variável e em quanto deve reduzir/aumentar o seu valor para a promoção da eficiência. Além disso, essas informações são igualmente úteis na mudança das práticas de gestão das propriedades.

Os modelos que estimaram a eficiência por grupos de produtores possibilitaram a identificação de classes de eficiência e permitiram traçar o perfil e caracterizar esses produtores com variáveis não incluídas nos modelos. Em geral, os produtores eficientes são aqueles que: têm telefone na propriedade e usam computadores para a agropecuária; fazem 
contabilidade da produção; têm energia elétrica e água para produção; possuem mapa ou escrituração do imóvel rural; não têm renda extraagrícola; fazem parte de entidades de representação ou de participação social; têm algum tipo de preocupação ambiental (fazem rotação de culturas, empregam práticas de conservação do solo etc.); fazem uso intensivo de insumos industriais.

O uso da variável "área cultivada" ao invés de "área total" pode causar alguns problemas, já que fornece resultados de eficiência técnica, mas não de uma eficiência global, pois desconsidera a razão entre terra disponível e em uso. O emprego da variável “área cultivada” aumenta a eficiência daqueles produtores que utilizam estufa e mascara o mau aproveitamento da terra. Já a variável "área total” penaliza aqueles agricultores quem têm reservas ambientais, não incluídas como fonte de produção e renda (GOMES, MANGABEIRA, 2004). Resultados de modelagem DEA para Holambra com o uso da variável “área total” podem ser vistos em Gomes et al. (2004).

Modelos DEA avançados podem melhorar os resultados obtidos, seja na redução dos pesos zero, seja na possibilidade de seleção de alvos a alcançar. Outro aspecto importante é o uso de variáveis não incluídas no modelo e que possam explicar as ineficiências e gerarem informações, para as instituições de pesquisa, desenvolvimento e extensão rural, no intuito de melhorar a eficiência dos produtores ineficientes, como, por exemplo, variáveis espaciais (tipo de solo, uso e cobertura das terras etc.) ou contextuais (socioeconômicas, ambientais etc.). Esses desenvolvimentos serão contemplados em estudos futuros.

\section{Referências bibliográficas}

ALI, A.I. Streamlined computation for data envelopment analysis. European Journal of Operational Research, v. 64, n. 1, p. 61-67, 1993.

ALLEN, R.; ATHANASSOPOULOS, A.; DYSON, R.G.; THANASSOULIS, E. Weights restrictions and value judgements in data envelopment analysis: evolution, development and future directions. Annals of Operations Research, n. 73, p. 13-34, 1997. 
ANGULO MEZA, L. Um enfoque multiobjetivo para modelos de determinação de alvos em DEA. Rio de Janeiro, 2002. Tese (Doutorado em Eng. Produção), Universidade Federal do Rio de Janeiro.

ANGULO MEZA, L.; BIONDI NETO, L.; SOARES DE MELLO, J.C.C.B.; GOMES, E.G. ISYDS - Integrated System for Decision Support (SIAD - Sistema Integrado de Apoio à Decisão): a software package for data envelopment analysis model. Pesquisa Operacional, v. 25, n. 3, 2005 (no prelo). ANGULO MEZA, L.; ESTELLITA LINS, M.P. Review of methods for increasing discrimination in data envelopment analysis. Annals of Operations Research, v. 116, p. 225-242, 2002.

AZEVEDO, E.C.; MANGABEIRA, J.A.C.; MIRANDA, J.R. Análise da sustentabilidade das atividades agrícolas: uma contribuição dos sistemas de informações geográficas na gestão ambiental e no desenvolvimento sustentado. In: CONGRESSO BRASILEIRO DE ADMINISTRAÇÃO RURAL, 4., 2001, Goiânia. Anais... Lavras: ABAR, 2001. 8p.

BANKER, R.D.; CHARNES, A.; COOPER, W.W. Some models for estimating technical scale inefficiencies in DEA. Management Science, v. 30, n. 9, p. 1078-1092, 1984.

BARR, R.S.; DURCHHOLZ, M.L.; SEIFORD, L. Peeling the DEA onion: layering and rank-ordering DMUs using tiered DEA. Technical Report, Southern Methodist University, 2000.

BISHOP, Y.; FIENBERG, S.; HOLLAND, P. Discrete multivariate analysis: theory and practice. Cambridge, Estados Unidos: MIT, 1975. 575 p.

CHARNES, A.; COOPER, W.W.; RHODES, E. Measuring the efficiency of decision-making units. European Journal of Operational Research, v. 2, p. 429-444, 1978.

COELLI, T.J.; RAO, D.S.P.; BATTESE, G.E. An introduction to efficiency and productivity analysis. Boston: Kluwer Academic Publishers, 1998, 296p.

DOYLE, J.R.; GREEN, R.H. Cross-evaluation in DEA: improving discrimination among DMU's. INFOR, v. 33, n. 3, p. 205-222, 1995.

ENTANI, T.; MAEDA, Y.; TANAKA, H. Dual models of interval dea and 
its extensions to interval data. European Journal of Operational Research, v. 136, p. 32-45, 2002.

EVERITT, B. Cluster analysis. London: Heinemann Educational, 1974. $122 \mathrm{p}$.

ESTELLITA LINS, M.P.; ANGULO-MEZA, L. Análise envoltória de dados e perspectivas de integração no ambiente de apoio à decisão. Rio de Janeiro: Editora COPPE/UFRJ, 2000.

GOMES, E.G. Modelos de análise de envoltória de dados com ganhos de soma zero. Rio de Janeiro, 2003. Tese (Doutorado em Engenharia de Produção), Universidade Federal do Rio de Janeiro.

FIGUEIREDO, D.S. Índice híbrido de eficácia e eficiência para loja de varejo. Niterói, 2005. Tese (Mestrado em Engenharia de Produção), Universidade Federal Fluminense.

GOMES, E.G.; MANGABEIRA, J.A.C. Uso de análise de envoltória de dados em agricultura: o caso de Holambra. Engevista, v. 6, n. 1, p. 19-27, 2004.

GOMES, E.G.; MANGABEIRA, J.A.C.; SOARES DE MELLO, J.C.C.B.; ANGULO MEZA, L. The use of data envelopment analysis in agriculture in the presence of interval data. In: Congreso Latino-Iberoamericano de Investigación Operativa - CLAIO, 12., 2004, La Habana. Memorias..., La Habana: ALIO, 2004.

GOMES, E.G.; SOARES DE MELLO, J.C.C.B.; BIONDI NETO, L. Avaliação de eficiência por análise de envoltória de dados: conceitos, aplicações à agricultura e integração com Sistemas de Informação Geográfica. Documentos, n. 28. Campinas: Embrapa Monitoramento por Satélite, 2003a.

GOMES, E.G.; SOARES DE MELLO, J.C.C.B.; ESTELLITA-LINS, M.P. Busca seqüencial de alvos intermediários em modelos DEA com soma de outputs constante. Investigação Operacional, v. 23, n. 2, p. 163-178, 2003b.

GONÇALVES, D.A. Avaliação de eficiência de fundos de investimentos financeiros: utilização de DMU artificial em modelos DEA com outputs negativos. Rio de Janeiro, 2003. Tese (Doutorado em Engenha- 
ria de Produção) - COPPE, Universidade Federal do Rio de Janeiro.

GONZÁLEZ ARAYA, M.C. Projeções não radiais em regiões fortemente eficientes da fronteira DEA - algoritmos e aplicações. Rio de Janeiro, 2003. Tese (Doutorado em Engenharia de Produção) - COPPE, Universidade Federal do Rio de Janeiro.

HOLAMBRA em números. Holambra Hoje, agosto, 1998. (3 $3^{a}$ capa).

INSTITUTO BRASILEIRO DE GEOGRAFIA E ESTATÍSTICA. Cidades@. 2002a. Disponível em: <http://www.ibge.gov.br/cidadesat/default. php > . Acesso em: 07 jun. 2004.

INSTITUTO BRASILEIRO DE GEOGRAFIA E ESTATÍSTICA. Sistema IBGE de Recuperação Automática - SIDRA. 2002b. Disponível em: < http:// www.ibge.gov.br/cidadesat/default.php > . Acesso em: 05 jun. 2004.

LETA, F.R.; SOARES DE MELLO, J.C.C.B.; GOMES, E.G.; ANGULOMEZA, L. Métodos de melhora de ordenação em DEA aplicados à avaliação estática de tornos mecânicos. Investigação Operacional, v. 25, 2005 (no prelo).

MANGABEIRA, J.A.C. Tipificação de produtores rurais apoiada em imagens de alta resolução espacial, geoprocessamento e estatística multivariada: uma proposta metodológica. Campinas, 2002. Dissertação (Mestrado em Planejamento e Desenvolvimento Rural Sustentável) - Faculdade de Engenharia Agrícola, UNICAMP.

NOVAES, L.F.L. Envoltória sob dupla ótica aplicada na avaliação imobiliária em ambiente do sistema de informação geográfica. Rio de Janeiro, 2002. Tese (Doutorado em Engenharia de Produção) - COPPE, Universidade Federal do Rio de Janeiro.

SEXTON, T.R.; SILKMAN, R.H.; LOGAN A.J. Data Envelopment Analysis: Critique and extensions. In: .H. Silkman (Ed.) Measuring efficiency: an assessment of data envelopment analysis. Jossey-Bass Editor, San Francisco, 1986.

SOARES DE MELLO, J.C.C.B.; GOMES, E.G.; BIONDI NETO, L.; ESTELLITA-LINS, M.P. Suavização da fronteira DEA: o caso BCC tridimensional. Investigação Operacional, v. 24, n. 1, p. 89-107, 2004. 
SOARES DE MELLO, J.C.C.B.; GOMES, E.G.; GOMES, L.F.A.M.; BIONDI NETO, L.; ANGULO MEZA, L. Avaliação do tamanho de aeroportos portugueses com relações multicritério de superação. Pesquisa Operacional, v. 25, n. 3, 2005 (no prelo).

SOUZA, G.S. Funções de produção: uma abordagem estatística com o uso de modelos de encapsulamento de dados. Texto para discussão, n. 17. Brasília: Embrapa Informação Tecnológica, 49p.

TAVARES, G. Data envelopment analysis: basic models and their main extensions. A model to analyse the modernisation of telecommunication services in OECD countries. Coimbra, 1998. Tese (Mestrado em Ciências e Tecnologia) - Universidade de Coimbra.

TUPY, O.; YAMAGUCHI, L.C.T. Identificando benchmarks na produção de leite. Revista de Economia e Sociologia Rural, v. 40, n. 1, p. 81-96, 2002.

Recebido em julho de 2004 e revisto em setembro de 2005 